\title{
Jaw dislocation during general anaesthesia
}

A case is reported of jaw dislocation on placement of an oral airway and nasagastric tube during an othenvise unremarkable exploratory laparotomy under general anaesthesia. The pathophysiology, diagnosis and Ireatment of jaw dislocation are described.

Anacsthetists routinely position airways and endotracheal tubes by opening the patient's mouth widely. While this is usually a benign procedure, the following case report illustrates that dislocation of the jaw requiring manipulation for restoration may occur.

\section{Case report}

The patient was a 27 -year-old $65 \mathrm{~kg}$ female who presented to the emergency ward with uterine perforation following a therapeutic abortion. Preanaesthetic evaluation revealed an ASA physical status I-E patient whose last food intake was five hours earlier. Laboratory findings were within normal limits. There was no history of previous general anaesthesia nor use of any medications. Her dentition was normal as was the ability to open the mouth and nex and extend the neck. A general anaesthetic for exploratory laparotomy was planned.

After pre-oxygenation, a rapid-sequence induction using thiopentone $350 \mathrm{mg}$ and succinylcholine $100 \mathrm{mg}$ was performed. The patient was intubated uneventfully, without the need to open the mouth widely, but rather just enough to accommodate a \#3 MacIntosh laryngoscope blade.

During placement of an oral airway and a naso-gastric tube, the mandible was widely opened and it remained open. On palpation, the condyles of the mandible could be

\section{Key words}

COMPLICATIONS: jaw dislocation; ANAESTHESIA: general

From the Department of Anesthesiology, Jefferson Medical College, Thomas Jefferson University, Philadelphia, Pennsylvania.

Address correspondence to: Dr. Mitchel Sosis, Thonas Jefferson University Hospital, Department of Anesthesiology, 10th \& Walnut Streets, 414 Main Building, Philadelphia, Pennsylvania 19107 felt below the zygomatic arch and a diagnosis of mandibular dislocation was made. Since the dislocation could not be readily reduced, manipulation of the mandible was necessary. Positioned in front of the patient, the anaesthetist placed his thumbs near the posterior teeth with his fingers grasping the lower edge of the mandible. Downward pressure on the posterior teeth and upward movement of the chin along with posterior displacement of the entire mandible readily reduced the dislocation. The operation was completed and extubation was accomplished without complication.

Postoperatively, the patient was visited and no pathology was noted on examination. The patient stated that on occasion her jaw "pops out," but she nornally carrects this herself.

\section{Discussion}

It has been recommended that a patient's mouth be widely opened during tracheal intubation.' This manoeuvre is also employed in placing oropharyngeal airways, oesophageal stethoscopes or guiding nasogastric tubes with a gloved hand in the oropharynx. Furthermore, anaesthetists are generally present during surgery in or about the oropharynx employing mouth gags which may open the mouth maximally.

Although jaw dislocation is not uncommon, ${ }^{2-5}$ a search of the anaesthetic literature found little mention of it, ${ }^{5,6}$ and no discussion of its treatment.

An understanding of the pathophysiology and treatment of jaw dislocation depends on a familiarity with the temporomandibular joint. Briefly, this joint is the articulation of the condyloid process of the mandible with the glenoid fossa of the temporal bone. It is unique among joints in the human body, since it can be dislocated without external force ${ }^{7}$ On opening the mouth, the condyloid process moves forward and is usually limited by the articular tubercle (eminentia articularis). Laxity of supporting ligaments will allow the condyle to move anteriorly past its normal open position. The result may be a dislocation that requires manipulation for reduction or it may be self-reducing. This may occur spontaneously as during a yawn or "when the jaws are forcibly dilated open during general andesthesia."

The diagnosis is usually obvious by the characteristic wide open mouth with the inability to close it. If the dislocation is unilateral the chin will be deviated away 


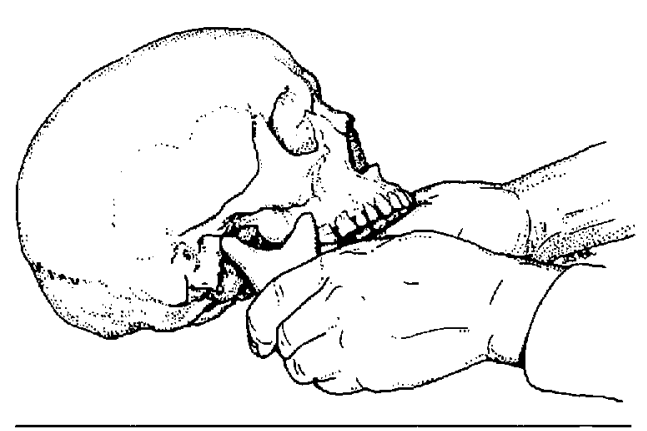

FIGURE Technique of reduction of mandibular dislocation. Operator exerts inferior pressure over the base of the coronoid as the first step in reducing dislacation. From: Lewis ${ }^{4}$, with permission.

from the dislocated side. Bilateral dislocations preserve the midline position of the chin. Awake patients will often complain of pain in the area of the temporomandibular joint. Palpation of the condyle (below the zygomatic arch) will confirm its absence from the glenoid fossa. Spontaneous movement of the mandible, if present at all, is usually restricted. $X$-rays of the temporomadibular joints will confirm the diagnosis.

Dislocations should be reduced early, since spasm of the external pterygoid and other muscles may ankylose the jaw so that surgical intervention will become necessary.

The dislocation can often be reduced ${ }^{3.4 .7}$ if the operator positions himself in front of the patient and places his thumbs near the posterior teeth with his fingers grasping the lower edge of the mandible (Figure). Downward pressure on the posterior teeth and upward movement of the chin, along with posterior displacement of the entire mandible should be applied. ${ }^{3}$ The anaesthetist may be in a unique position to perform this treatment since muscle relaxation is often of great benefit in repositioning the condyle.

Henny $y^{3}$ noted cases of dislocation of long duration in patients who had received general anaesthesia with the use of mouth gags for dental extractions and tonsillectomies. One patient appeared surprisingly normal with this dislocation. The dislocation might therefore be overlooked. The anaesthetist should determine that the mandible is restored whenever it has been widely opened.

An awareness of the potential for jaw dislocation during routine anaesthetic or surgical manoeuvres is important. The informed anaesthetist is in an ideal position to diagnosis and treat most of these dislocations.

\section{References}

1 Salem MR, Mathrubhutham $M$, Bennett EJ. Difficult intubation. N Engl J Med 1976; 295: 879-81.

2 Hale RH. Treatment of recurrent dislocation of the mandible: revicw of literature and report of cases. $J$ Oral Surg 1972; 30: 527-30.

3 Henny FA. The temporomandibular joint. Textbook of Oral and Maxillofacial Surgery. p 413. Edited by Kruger GO, St. Louis: C. V. Mosby, 1979.

4 Lewis JES. A simple technique for reduction of long-standing dislocation of the mandible. Br J Oral Surg 1981; 19: 52-6.

5 Patal A. Jaw dislocation during anaesthesia. Anaesthesia 1979; 34: 376.

6 Bellman $M H, B a b u K V R$. Jaw dislocation during anaesthesia. Anaesthesia 1978; 33: 844.

7 Winer HJ. Reduction of acute dislocation of the mandible. J Calif Dent Assn 1976; 4: 60-3.

\section{Résumé}

On rapporte un cas de dislocation de la mâchoire au moment de la mise en place d'une canule orale et d'une sonde nasogastrique lors d'une luparotomie exploratrice sans particularité faite sous anesthésie générale. La pathophysiologie, le diagnos. tic et le traitement de la dislocation de la mâchoire sont décrits. 